13 Jones PW, Quirk FH, Baveystock CM, Littlejohns P. A self-complete measure of health status for chronic airflow limitation. The St George's respiratory questionnaire. Am Rev Respir Dis 1992;145:1321-7.

14 Meecham Jones DJ, Paul EA, Jones PW, Wedzicha JA. Nasal pressure support ventilation plus oxygen compared with oxygen therapy alone in hypercapnic COPD. Am J Respir Crit Care Med 1995;152:538-44.

15 Goldstein H. Multilevel statistical models. 2nd ed. London: Edward Arnold, 1995.

16 Bryk AS, Raudenbush SW. Hierarchical linear models. London: Sage Publications, 1992.

17 Van Elteren PH. On the combination of independent two-sample tests of Wilcoxon. Bull Int Stat Inst 1960;37:351-61.

18 Dompeling E, van Schayck CP, van Grunsven PM, van Herwaarden CL Akkermans R, Molema J, et al. Slowing the deterioration of asthma and chronic obstructive pulmonary disease observed during bronchodilator therapy by adding inhaled corticosteroids. A 4 -year prospective study. Ann Intern Med 1993;118:770-8.

19 an Grunsven PM, van Schayck CP, Derenne JP, Kerstjens HA, Renkema TE, Postma DS, et al. Long term effects of inhaled corticosteroids in chronic obstructive pulmonary disease: a meta-analysis. Thorax $1999 ; 54: 7-14$.
20 Seemungal TA, Donaldson GC, Paul EA, Bestall JC, Jeffries DJ, Wedzicha JA. Effect of exacerbation on quality of life in patients with chronic obstructive pulmonary disease. Am J Respir Crit Care Med 1998;157:141822.

21 Paggiaro PL, Dahle R, Bakran I, Frith L, Hollingworth K, Efthimiou J Multicentre randomised placebo-controlled trial of inhaled fluticasone propionate in patients with chronic obstructive pulmonary disease. propionate in patients

22 Jarad NA, Wedzicha JA, Burge PS, Calverley PMA for the ISOLDE study group. An observational study of inhaled corticosteroid withdrawal in stable chronic obstructive pulmonary disease. Respir Med 1999;93:161-6.

23 Osman LM, Godden DJ, Friend JAR, Legge JS, Douglas JG. Quality of life and hospital re-admission in patients with chronic obstructive pulmonary disease. Thorax 1997;52:67-71.

24 Li JTC, Ford LB, Chevinsky P, Weisberg SC, Kellerman DJ, Faulkner KG, et al. Fluticasone propionate powder and lack of clinically significan effects on hypothalamic-pituitary-adrenal axis and bone mineral density over 2 years in adults with mild asthma. J Allergy Clin Immunol $1999 ; 103: 1062-8$

(Accepted 7 February 2000)

\title{
Comparing health inequality in men and women: prospective study of mortality 1986-96
}

\author{
Amanda Sacker, David Firth, Ray Fitzpatrick, Kevin Lynch, Mel Bartley
}

\begin{abstract}
Objectives To study prospectively the differences in health inequality in men and women from 1986-96 using the Office for National Statistics' longitudinal study and new socioeconomic classification. To assess the relative importance of social class (based on employment characteristics) and social position according to the general social advantage of the household to mortality risk in men and women.

Design Prospective study.

Setting England and Wales.
\end{abstract}

Subjects Men and women of working age at the time of the 1981 census, with a recorded occupation.

Main outcome measures Mortality.

Results In men, social class based on employment relations, measured according to the Office for National Statistics' socioeconomic classification, was the most important influence on mortality. In women, social class based on individual employment relations and conditions showed only a weak gradient. Large differences in risk of mortality in women were found, however, when social position was measured according to the general social advantage in the household. Conclusions Comparisons of the extent of health inequality in men and women are affected by the measures of social inequality used. For women, even those in paid work, classifications based on characteristics of the employment situation may give a considerable underestimate. The Office for National Statistics' new measure of socioeconomic position is useful for assessing health inequality in men, but in women a more important predictor of mortality is inequality in general social advantage of the household.

\section{Introduction}

Social variation in morbidity and mortality in women whose social position is measured according to their own occupation is often found to be less than that of men. ${ }^{1-4}$ The extent of social inequality in women's health is known to be particularly sensitive to the way in which inequality is defined and measured. ${ }^{156}$ When women's social position is classified according to the occupation of their male partners, male and female health gradients are more similar. ${ }^{78}$ In estimates of health inequality there is comparatively little discussion of these apparent sex differences.

It is now possible to study sex differences in health inequality with distinct validated measures of social position and advantage, one based on relations and conditions of employment and the other on material cultural aspects of lifestyle outside the workplace. The Office for National Statistics (ONS) has recently adopted a new measure of social inequality: the ONS socioeconomic classification, for use in the 2001 census and official surveys. ${ }^{9}$ This measure allocates occupations to social classes on the basis of aspects of the work situation, in particular the extent to which members of an occupation have control over their own work and that of others.

The other measure is the Cambridge scale, which is based on general social and material advantage and lifestyle as reflected in choices of friendship. ${ }^{10-12}$ Both measures are being increasingly used in health studies and have been found to be related to mortality, morbidity, and health related behaviour. ${ }^{13-18}$

We aimed to determine whether social gradients in mortality in women in England and Wales during 1986-96 were less noticeable than in men, and whether this depended on the measure of social inequality used.

\section{Subjects and methods}

\section{Sample}

The ONS longitudinal study is an approximate $1 \%$ sample of the population of England and Wales. Sampling was begun at the time of the 1971 census when all those born on any one of four days in the year were entered into the dataset. The study is regularly updated to include new members born on any one of the four designated dates. ${ }^{19}$ Vital events including mortality are
Editorial by Vågerö

Department of Epidemiology and Public Health, Royal Free and University College London Medical School, London

WC1E 6BT

Amanda Sacker senior research fellow Mel Bartley principal research fellow

Nuffield College, Oxford OX1 1NF

David Firth senior fellow in statistics for the social sciences

Institute of Health Sciences, University of Oxford, Oxford OX3 7LF

Ray Fitzpatrick professor of public health and primary care

continued over

BMJ 2000;320:1303-7

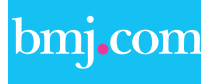

Some occupations according to ONS classes and the Cambridge scale appear on the $B M J$ 's website 
Centre for

Longitudinal

Studies, Institute of

Education, London

WC1H 0AI

Kevin Lynch

computing research

officer

Correspondence to:

M Bartley

mel@public-health. ucl.ac.uk linked to the data from successive censuses. Aggregated data from the study are available to academics subject to strict controls to preserve confidentiality. ${ }^{19}$ For our study we included all those who were aged 16 to 65 (16 to 60 for women) and in paid work at the time of the 1981 census and who were still alive in 1986. Those who die within five years of a census are not included in mortality analyses of this dataset to reduce selection bias. ${ }^{20}$ Thus we included all cause mortality from 1986-96 in our analyses.

\section{Measurement of social position}

We used two measures of social position, the Cambridge scale and the ONS socioeconomic classification. These measures have been developed by research using explicit criteria.

\section{ONS socioeconomic classification}

This schema primarily distinguishes between employers and employees. Distinctions are made between employees whose work concerns higher and lower amounts of planning and supervision of their own work and that of others, degrees of job security, and the existence or not of a career structure. ${ }^{9}$ We used a seven category version of the ONS socioeconomic classification (table 1). Higher managers are those in establishments with more than 25 staff; lower managers are those in smaller establishments. Professional occupations are divided into employees who have total or main responsibility for planning their own and others' work (professionals) and those whose work is to a greater extent determined by others (associate professionals). Occupations with some autonomy but not overall planning or supervision within clerical, sales, and technical forms of work are classified as intermediate. Employees with supervisory responsibility for the work of intermediate workers are classified as higher supervisors. Employees with neither planning nor supervisory roles fall into three groups: those engaged in craft occupations (craft and related) and those engaged partly or wholly in routine work (semiroutine or routine workers). Employees with supervisory responsibility for craft and routine workers but

Table 1 Office for National Statistics' socioeconomic classification

\begin{tabular}{|c|c|c|c|}
\hline $\begin{array}{l}13 \text { category } \\
\text { classes }\end{array}$ & Description & $\begin{array}{l}7 \text { category } \\
\text { classes }\end{array}$ & Description \\
\hline L1 & Employers in large firms (>25 staff) & 1 & Higher managerial and professional \\
\hline $\mathrm{L} 2$ & Managers in large firms & & \\
\hline L3 & Professionals & & \\
\hline L4 & Associate professionals & 2 & Lower managerial and professionals \\
\hline L5 & Managers in small firms & & \\
\hline L6 & $\begin{array}{l}\text { Higher supervisors (supervisors of } \\
\text { intermediate workers) }\end{array}$ & & \\
\hline L7.1 & Clerical and secretarial & 3 & Intermediate occupations \\
\hline L7.2 & $\begin{array}{l}\text { Intermediate public service } \\
\text { occupations }\end{array}$ & & \\
\hline L7.3 & Intermediate technical occupations & & \\
\hline L8.1 and 8.2 & Employers in small firms & 4 & $\begin{array}{l}\text { Small employers and own account } \\
\text { occupations }\end{array}$ \\
\hline L9.1 and 9.2 & $\begin{array}{l}\text { Non-professional self employed } \\
\text { occupations }\end{array}$ & & \\
\hline L10 & $\begin{array}{l}\text { Supervisors of craft and routine } \\
\text { occupations }\end{array}$ & 5 & $\begin{array}{l}\text { Lower supervisors, craft and related } \\
\text { occupations }\end{array}$ \\
\hline $\mathrm{L} 11$ & Craft and related occupations & & \\
\hline L12 & Semiroutine occupations & 6 & Semiroutine occupations \\
\hline L13 & Routine occupations & 7 & Routine occupations \\
\hline
\end{tabular}

who have no overall planning role are classified as lower supervisors. ${ }^{921}$ The classification does not distinguish between manual and non-manual work because "changes in the nature and structure of both industry and occupations has rendered this distinction both outmoded and misleading." ${ }^{9}$ The concept of routine work has replaced that of skilled work. In the modern context, and most importantly in relation to women's occupations, it is far more relevant to know the extent to which an employee determines the content of their own work or has this laid down as a routine set by others, rather than the extent to which it concerns manual skills. The development of the classification system has involved extensive validation studies. ${ }^{21}$

\section{Cambridge scale}

The Cambridge scale was originally derived from surveys by asking the occupations of the best friends and marriage partners of respondents, on the grounds that choices of marriage and friendship are the most important expression of perceived equality. ${ }^{1022}$ Those pairs of occupations whose members seldom cited each other as friends were regarded as separated by a greater social distance, and those frequently cited, as less distant from each other. After ascertaining the comparative distances between all pairs of occupations, multidimensional scaling was used to extract the principal dimensions of the space so defined. This exercise yielded a single major dimension, supporting the concept of a single hierarchy of social interaction and social advantage ${ }^{12}{ }^{23}$ : the score on this factor is the Cambridge score. The Cambridge scale is derived from observed patterns of social interaction and makes no reference to employment relations or conditions as a source of social inequality.

For our analysis we allocated men and women to the ONS socioeconomic classes by their own occupation. Because this approach considers general social advantage and its associated lifestyle as influenced by both men and women's own and their partner's occupation, ${ }^{24}$ each man and woman was allocated the higher of their own or their partner's Cambridge score if married or cohabiting. Single people living alone or as members of larger household groups were allocated a score on the basis of their own occupation. Figure 1 shows the relation between the ONS socioeconomic classes and the Cambridge score (ranked into septiles). It shows that there is a large proportion of the population whose position is assessed differently by the two classification systems.

\section{Methods of analysis}

We carried out separate analyses for men and women using Cox regression models controlling for age in five year bands. The risk of mortality in each social group is compared with that for all men or women, which is set to 1. We first carried out analyses with social class based on employment conditions (ONS socioeconomic classification) and general social advantage (Cambridge scale) predicting mortality separately. Because the two measures overlapped, we used multivariate models to assess whether there were separate independent effects of each one, and to compare the two. To compensate for the fact that the ONS socioeconomic classification is measured as seven categories whereas the Cambridge scale is a continuous measure, we ranked the Cambridge 


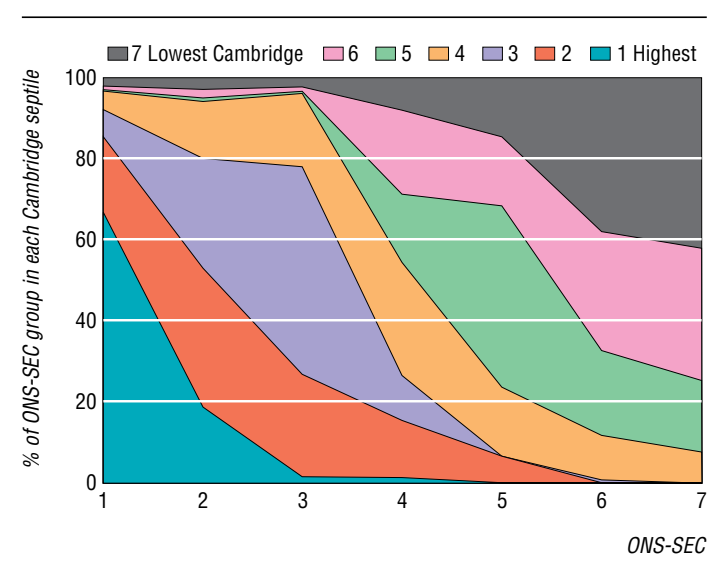

Fig 1 Relation between Office for National Statistics' socioeconomic classes and Cambridge score

scores into seven groups ordered from greatest to least household advantage before being entered into the analyses.

\section{Results}

Table 2 shows the distribution of men and women among the categories of the ONS socioeconomic classes. Table 3 shows the age adjusted risk of mortality in men and women by their ONS socioeconomic classification and Cambridge scale compared with the overall risk in all men or all women. Employees with greater autonomy, security, and career structure (ONS socioeconomic classes 1 and 2) had a significantly lower risk of mortality than all men, as did self employed workers. Lower level supervisors and craft workers had higher mortality than all those in managerial and professional occupations or self employed workers but significantly lower mortality than semiroutine workers. Workers in routine occupations had significantly higher mortality than those in semiroutine occupations. With the exception of intermediate and self employed workers, mortality was
Table 2 Distribution of men and women by Office for National Statistics' socioeconomic classes. Values are numbers (percentages)

\begin{tabular}{llcc}
$\begin{array}{l}\text { Socioeconomic } \\
\text { class }\end{array}$ & Description & \multicolumn{1}{c}{ Men } & Women \\
\hline 1 & Higher managerial and professional & $20179(13.9)$ & $7973(8.8)$ \\
\hline 2 & Lower managerial and professional & $23497(16.2)$ & $12119(13.4)$ \\
\hline 3 & Intermediate employees & $11029(7.6)$ & $27469(30.4)$ \\
\hline 4 & Small employers or own account & $11992(8.3)$ & $2836(3.1)$ \\
\hline 5 & Lower supervisors, craft and related & $26242(18.1)$ & $2957(3.3)$ \\
\hline 6 & $\begin{array}{l}\text { Employees in semiroutine } \\
\text { occupations }\end{array}$ & $41342(28.6)$ & $21129(23.4)$ \\
\hline 7 & Employees in routine occupations & $10475(7.2)$ & $15844(17.5)$ \\
\hline Total & & $144756(100)$ & $90327(100)$ \\
\hline
\end{tabular}

statistically distinct for each group (confidence intervals did not overlap).

Mortality patterns in working women by the ONS socioeconomic classes are less clear. Higher managerial and professional women and intermediate workers (a large group in women) had significantly lower mortality than all other groups. Mortality risk in lower supervisors and women with semiroutine and routine occupations was significantly higher than the average for all working women, but these groups had similar risk levels to each other and to lower professional and self employed women (with average mortality). In contrast, mortality differences among women were substantial when expressed in terms of general social advantage as assessed by the Cambridge scale.

Table 3 shows the results of adjusting each measure of social position for the other. In men, social class based on employment relations (ONS classification) was found to have greater explanatory power than general social and material advantage (Cambridge scale) according to the difference in $\chi^{2}$ before and after adjustment, although both measures attenuate the effect of each other. In women, both measures made a significant independent contribution also, but the ONS classification had far less explanatory power than general social and material advantage both before and after adjustment. For women, the general social and material advantage of the household had a greater

Table 3 Age adjusted relative risk of mortality for men and women by Office for National Statistics' socioeconomic classes and Cambridge septiles. Values are odds ratios $(95 \% \mathrm{Cls})$ unless stated otherwise

\begin{tabular}{|c|c|c|c|c|}
\hline & \multicolumn{2}{|c|}{ Men } & \multicolumn{2}{|c|}{ Women } \\
\hline & Univariate & Multivariate & Univariate & Multivariate \\
\hline \multicolumn{5}{|c|}{ Office of National Statistics' socioeconomic class } \\
\hline 1 Higher managerial and professional & $0.74(0.70$ to 0.77$)$ & 0.83 (0.77 to 0.91$)$ & 0.75 (0.67 to 0.84$)$ & $0.99(0.85$ to 1.15$)$ \\
\hline 2 Lower managerial and professional & $0.86(0.82$ to 0.90$)$ & $0.90(0.85$ to 0.96$)$ & 1.08 (0.99 to 1.18$)$ & $1.26(1.14$ to 1.40$)$ \\
\hline 3 Intermediate employees & 0.96 (0.91 to 1.02$)$ & $0.92(0.86$ to 0.98$)$ & 0.86 (0.80 to 0.93$)$ & $1.03(0.94$ to 1.13$)$ \\
\hline 4 Small employers or own account & 0.94 (0.89 to 0.99$)$ & $0.93(0.88$ to 0.99$)$ & 1.00 (0.86 to 1.15$)$ & $1.08(0.93$ to 1.26$)$ \\
\hline 5 Lower supervisors, craft and related & 1.09 (1.05 to 1.13$)$ & 1.06 (1.01 to 1.11$)$ & 1.16 (1.02 to 1.33$)$ & $0.92(0.79$ to 1.06$)$ \\
\hline 6 Employees in semiroutine occupations & $1.18(1.14$ to 1.21$)$ & $1.13(1.08$ to 1.19$)$ & 1.08 (1.01 to 1.16$)$ & $0.92(0.84$ to 0.99$)$ \\
\hline 7 Employees in routine occupations & $1.38(1.31$ to 1.45$)$ & 1.30 (1.21 to 1.38$)$ & 1.14 (1.06 to 1.22$)$ & $0.86(0.78$ to 0.94$)$ \\
\hline$\Delta \chi^{2 \star}, \mathrm{P}$ value & $454,<0.0001$ & $68,<0.0001$ & $66,<0.0001$ & $29,0.0001$ \\
\hline \multicolumn{5}{|l|}{ Cambridge scale } \\
\hline 1 Greatest advantage & 0.72 (0.69 to 0.76$)$ & $0.86(0.79$ to 0.94$)$ & 0.81 (0.74 to 0.88$)$ & 0.77 (0.69 to 0.87$)$ \\
\hline 2 & 0.85 (0.81 to 0.89$)$ & 0.96 (0.90 to 1.02$)$ & 0.74 (0.67 to 0.82$)$ & 0.71 (0.64 to 0.78$)$ \\
\hline 3 & 1.01 (0.97 to 1.05$)$ & 1.07 (1.01 to 1.12 ) & 0.87 (0.78 to 0.97$)$ & $0.81(0.72$ to 0.90$)$ \\
\hline 4 & 1.04 (0.99 to 1.08$)$ & 1.00 (0.95 to 1.05$)$ & 1.07 (0.99 to 1.15$)$ & 0.99 (0.91 to 1.08) \\
\hline 5 & 1.09 (1.05 to 1.14$)$ & 1.00 (0.95 to 1.05) & 1.03 (0.94 to 1.12) & $1.06(0.97$ to 1.17$)$ \\
\hline 6 & 1.14 (1.10 to 1.19$)$ & 1.05 (0.99 to 1.10) & 1.24 (1.15 to 1.33 ) & 1.37 (1.25 to 1.51$)$ \\
\hline 7 Least advantage & $1.25(1.20$ to 1.29$)$ & 1.08 (1.03 to 1.14$)$ & 1.42 (1.33 to 1.52$)$ & 1.57 (1.44 to 1.72) \\
\hline$\overline{\Delta \chi^{2 *}, \mathrm{P} \text { value }}$ & $409,<0.0001$ & $23,0.0008$ & $174,<0.0001$ & $136,<0.0001$ \\
\hline
\end{tabular}




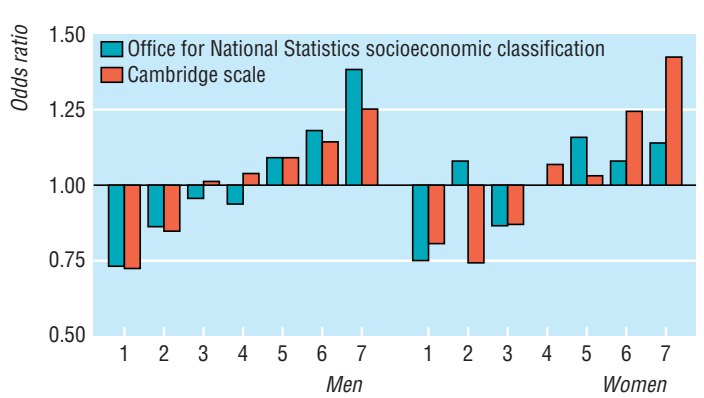

Fig 2 Age adjusted relative risk of mortality by Office for National Statistics' socioeconomic classes and Cambridge scale for men and women

independent effect on mortality than social class based on employment relations. The gradient in women's mortality by household advantage (Cambridge scale) is steeper after adjusting for employment relations and conditions (ONS classification).

Figure 2 shows the differences between the ONS classification and the Cambridge scale in predicting mortality. In men, the mortality gradient between the "top" and "bottom" of the ONS classification is steeper than that with the Cambridge scale. The reverse situation is observed for women. The overall gradient between the ONS socioeconomic classes is both uneven and comparatively shallow whereas the mortality gradient with the Cambridge score shows a greater degree of inequality. The mortality risks in the top and bottom septiles of the Cambridge scale indicate that women with the least social and material advantage have roughly 1.75 times the risk of mortality of women with the greatest advantage, almost exactly the same ratio as that found in men.

\section{What is already known on this topic}

Health inequality in women is studied far less often than in men, one reason being uncertainty about the best way to measure social inequality in women

Studies that use measures of social inequality based on their own occupation tend to show far less health inequality in women

Some studies have used measures of inequality based on concepts of deprivation or income, and these have tended to show comparatively greater extents of health inequality in women, but there are no studies using measures of inequality based on shared culture or common lifestyle

\section{What this study adds}

An analysis of data from $1 \%$ of the population of England and Wales, followed up from 1981-96, showed that in men the Office for National Statistics' new validated measure of social inequality based on employment relations and conditions produced clear differences in life expectancy between social groups

This measure, however, showed far less inequality in women

When a measure of social inequality based on general social advantage and lifestyle of the household was used, the extent of inequality in life expectancy was more or less identical in men and women

\section{Discussion}

Even at a time of women's high participation in employment, the social basis for health inequalities still seems to differ according to sex. In men, the ONS socioeconomic classification, the government's new measure of social class, based on relations and conditions of employment produces a set of groups with a distinct risk of mortality that differ not just between higher managers and professionals and routine employees but throughout its full range. In women the effect of this variable was dwarfed by general social advantage. Both the ONS classification and the household Cambridge scale produced a range of relative mortality from around $25 \%$ below to $30 \%$ above the average for all men, whereas for women the two dimensions of social position did not capture the same variability in risk of mortality. In particular, women working in occupations with the least favourable conditions of employment had a $14 \%$ increased risk of mortality compared with the average, whereas women in households with least general social advantage had a $40 \%$ increased risk.

The difference in health inequality in women when using a measure of the general social advantage of the household rather than a measure based on occupational characteristics may have several explanations. Although women in their 20s and 30s will spend far more time in paid work than their mothers' generation, the great majority of deaths among women aged up to 59 take place at the higher end of this age range. Over their full life course these women will still have spent comparatively less time in the workplace than their male peers. So if routine work with little autonomy or opportunity for career advancement is simply regarded as a hazard, women have less exposure time. Secondly, the Cambridge scale has been shown to be more strongly related to health behaviours than are other measures of social position. ${ }^{18}$ This is not surprising given that it is derived from choices of friendship, which will reflect shared leisure pursuits and lifestyle. In women the importance of employment related factors relative to lifestyle outside the workplace would be expected to differ from that in men, once again due to differential exposure. Finally, the power of the Cambridge scale to predict mortality in women may also reflect the nature of women's "double day." Working women (all in this analysis) in less advantaged households return home to a heavier burden of domestic labour, most of which falls on their shoulders, the disadvantage of their home situation amplifying any effects of work stresses and hazards. This is supported by the shape of the gradient relating general social advantage to mortality in women. At middle to higher levels of advantage, the gradient is less steep. In contrast with that of men, the risk of mortality in women increases sharply at the lower levels of advantage.

\section{Conclusion}

We have taken a new approach to understanding how health inequality differs between men and women. We have used separate measures of two different dimensions of social inequality that explicitly distinguish the effects of employment relations and conditions and general social advantage of the household. Our study 
shows that the relative importance of these dimensions is different in men and women and that the extent of health inequality in women compared with men is affected by the choice of measure.

Although social class based on employment relations was strongly related to risk of mortality in men, the relation of general social and material advantage in women was clearly dominant even in those who were employed at the time of the 1981 census. Additionally, the extent of inequality in women classified according to the level of general social advantage of their household is almost exactly that of men. Therefore any analysis that examines health inequality in women using only a measure of social position based on employment relations or conditions runs the risk of underestimating the size of the phenomenon. A better understanding of health inequality is possible when measures are used that are sensitive to the multidimensional nature of social inequality and the uneven effects of these dimensions on men and women.

We thank the Office for National Statistics for allowing the use of its longitudinal study. The Office for National Statistics bears no responsibility for the analysis and interpretation expressed here

Funding: This work was funded by the UK Economic and Social Research Council's social variations programme (grant No L128251001) and the Medical Research Council (grant No G8802774).

Contributors: AS, MB, RF, and DF participated in setting the research question and designing the paper. KL designed and constructed consistent social class measures and derived the socioeconomic classifications for the 1981 census and linked them to the census data. AS and KL carried out the data analysis. All authors participated in writing the paper and approved the final version. MB will act as guarantor for the paper

Competing interests: None declared.

1 Koskinen S, Martelin T. Why are socioeconomic mortality differences smaller among women than among men. Soc Sci Med 1994;38:1385-96.

2 Stronks K, van de Mheen H, van den Bos J, Mackenbach JP. Smaller socioeconomic inequalities in health among women: the role of employment status. Int J Epidemiol 1995;24:559-68.

3 Soni Raleigh K, Kiri V. Life expectancy in England: variations and trends by gender, health authority and level of deprivation. J Epidemiol Community Health 1997;51:649-58.
4 Macintyre S, Hunt K. Socio-economic position, gender and health: how do they interact? J Health Psychol 1997;2:315-34.

5 Macran S, Clarke L, Sloggett A, Bethune A. Womens socioeconomicstatus and self-assessed health-identifying some disadvantaged groups. Sociol Health Illness 1994;16:182-208.

6 Arber S. Comparing inequalities in women's and men's health: Britain in the 1990s. Soc Sci Med 1997;44:773-87.

7 Moser KA, Pugh HS, Goldblatt PO. Inequalities in women's health-looking at mortality differentials using an alternative approach. BMJ 1988;296:1221-4.

8 Dahl E. Inequality in health and the class position of women: the Norwegian experience. Sociol Health Illness 1991;13:491-505.

9 Rose D, O'Reilly K. Final report of the ESRC review of government social classifications. Swindon: Economic and Social Research Council and Office for National Statistics, 1998.

10 Stewart A, Prandy K, Blackburn RM. Social stratification and occupations. London: Macmillan, 1980.

11 Blackburn RM, Marsh C. Education and social class: revisiting the 1944 education act with fixed marginals. Br J Sociol 1991;42:507-36.

12 Prandy K. The revised Cambridge scale of occupations. Sociology 1990;24:629-55

13 Fitzpatrick R, Bartley M, Dodgeon B, Firth D, Lynch K. Social variation in health: relationship of mortality to the interim revised social classification. In: Rose D, O’Reilly K, eds. Constructing classes. Swindon: Economic and Social Research Council and Office for National Statistics, 1997:93-7.

14 Chandola T. Social inequality in coronary heart disease: a comparison of occupational classifications. Soc Sci Med 1998;47:525-33.

15 Prandy K. Class, stratification and inequalities in health: a comparison of the registrar-general's and the Cambridge scale. Sociol Health Illness 1999;21:466-84.

16 Dollamore G. Examining adult and infant mortality rates using the NS-ONS. Health Stat Q 1999;2:33-40.

17 Arber S. Insights about the non-employed, class and health: evidence from the general household survey. In: Rose D, O'Reilly K, eds. Constructing classes. Swindon: Economic and Social Research Council and Office for National Statistics, 1997:78-92.

18 Bartley M, Sacker A, Firth D, Fitzpatrick R. Understanding social variation in cardiovascular risk factors in women and men: the advantage of theoretically based measures. Soc Sci Med 1999:49:831-45.

19 Hattersley L, Creeser R. Longitudinal study 1971-1991: history, organisation and quality of data. London: HMSO, 1995

20 Leon D, Goldblatt P, Fox J. Social-class and mortality in occupational cohorts. Am J Ind Med 1992;22:141-2.

21 Rose D, O'Reilly K. Constructing classes: towards a new social classification for the UK. Swindon: Economic and Social Research Council and Office for National Statistics, 1997.

22 Marsh C, Blackburn RM. Class differences in access to higher education in Britain. In: Burrows R, Marsh C, eds. Consumption and class: divisions and change. London: Macmillan, 1992:184-211.

23 Prandy K. Sociological research group working paper 18. Cambridge: Social and Political Sciences, Cambridge University, 1990.

24 Marshall G, Roberts S, Burgoyne C, Swift A, Routh D. Class, gender and the asymmetry hypothesis. Eur Sociol Rev 1995;11:1-15.

(Accepted 7 February 2000)

\section{The right place at the right time}

On 25 November 1999 I was chairing a GP study day in cardiology at Harefield Heart Hospital. The first lecture was on chest pain. As this was being delivered I developed a severe "indigestion" pain which intensified. During the second lecture, given by a gastroenterologist, I had to leave the room. I met a very helpful drug representative who gave me paracetamol and milk but without benefit. She called one of the cardiologists who walked me across the road for an electrocardiogram.

I was soon strapped up. The electrocardiograph showed ST segment elevation in the anterior leads. I knew that my "indigestion" theory had evaporated. The words of the first lecturer came back to me: "If ever I develop angina please do an angiogram right away." The same cardiologist came by and said, "We're going to do an angiogram."

I was soon viewing my own coronary arteries on the screen. "There is a severe blockage in the anterior descending and right coronary," they said. I soon learnt that angioplasty had succeeded in keeping flow in the artery and muscle, but there was still the risk of severe infarction.

In my diamorphic dream state I was asked whether I wanted surgery. It was explained to me that angioplasty alone might be sufficient, but lack of certainty placed my life at risk. I willingly agreed. Apparently, my condition had to be further stabilised before being taken to surgery. Soon afterwards the surgeon was harvesting my left internal mammary artery and left radial to complete the revascularisation.

I later learnt that he then walked across to the lecture room to give his prepared talk, still in surgical greens. During the study day both cardiologists and the surgeon gave their lectures and attended to me.

It is good to be back home feeling well after surgery. I wonder which study day I will choose next year. Are they better to be avoided or is it better to be in the right place at the right time?

John D Cowan general practitioner, Harefield, Middlesex

We welcome articles of up to 600 words on topics such as A memorable patient, A paper that changed my practice, My most unfortunate mistake, or any other piece conveying instruction, pathos, or humour. If possible the article should be supplied on a disk. Permission is needed from the patient or a relative if an identifiable patient is referred to. We also welcome contributions for "Endpieces," consisting of quotations of up to 80 words (but most are considerably shorter) from any source, ancient or modern, which have appealed to the reader. 